\title{
Analysis of susceptibility of inflammable tobacco products dust to ignition from a heated surface
}

\author{
Marzena Półka ${ }^{1, *}$ \\ ${ }^{1}$ The Main School of Fire Service, Fire Safety Engineering Department, 52/54 Slowackiego St., \\ 01-629 Warsaw, Poland
}

\begin{abstract}
In the article was described combustible properties of tobacco product dust. Those properties decide about fire and explosion hazard for dust in layer and in cloud according to PN-EN 50281-2-1:2002 and PN-EN ISO/IEC 80079-20-2. There were determined protection against fire and explosion requirements of buildings structural elements and appliances used in space where dust accumulates. The article also consists safety requirements of using appliances in explosion hazard areas according to PN-EN 60079-14:2014. In the article are presented results of minimal ignition temperature of layer (MITL) and minimal ignition temperature of cloud dust (MTCD) as a function of dust layer thickness of chosen tobacco product and values of maximum acceptable surface temperature (MAST) of machines operating in the presence of dust cloud and chosen dust layer with thickness of 5 and $12.5 \mathrm{~mm}$.
\end{abstract}

\section{Introduction}

Poland is the top tobacco processor in the European Union and the biggest producer of ready tobacco products (cigarettes and smoking tobacco). Of 31 European tobacco product plants, six are operating in Poland. Export production constitutes an important element of Poland's trade balance in the agricultural and foodstuff segment. The tobacco industry provides almost PLN 20 billion annually, which constitutes $8 \%$ of total budgetary revenues. This is a big share, quite uncommon in other EU countries. The tobacco industry employs over 60 thousand persons (growers and employees working in production and in the processing industry) and produces ca. 40000 tonnes of tobacco annually, with two tobacco varieties prevailing - light Virginia tobacco and the dark variety called Burley [1]. The size of crushed fragments of tobacco leaves has a great impact on the combustion rate. The finer the material, the easier it ignites and the quicker it spreads fire. Special presses and sieves are used to crush the plants, which prepare tobacco fragments of appropriate size in a mechanical way. The State Fire Service is one of the institutions that specialise in the organisation of safety in industry. Its tasks also comprise the elimination of hazards posed by flammable dust. The damage which can be incurred as an effect of explosions of fragmented inflammable substances can prove to be quite extensive. Frequent consequences

${ }^{*}$ Corresponding author: mpolka@sgsp.edu.pl 
include not only damage to devices and machines, but also the collapse of building structures in which ignition took place and the destruction of walls in adjacent facilities [27]. The explosion of inflammable dusts may take place in all production stages, especially in the tobacco industry [6], starting from transport and processing, to storage and warehousing, especially in cases when the basic requirements related to fire safety are not met. An important role from the viewpoint of fire protection safety is to prevent possible explosions. This can be done among others by:

- eliminating sources which could lead to the ignition of material and meeting requirements of relevant applicable regulations related to fire protection,

- avoiding the accumulation of dust in prohibited places by assuring on-going inspections and keeping the premise clean, eliminating leaks of appliances and spillage of substances, - preventing the creation of explosive atmosphere in machines, for example by executing technological processes in the presence of a neutral gas.

The requirements of fire and explosion protection are not only applicable to structural elements of buildings, in which flammable dust can be present, but also to devices used inside them. All systems, such as electric systems or ventilation, which may cause accidental ignition of combustive dust and air mixture, have to be suitably protected from the permeation of substances (especially incandescent fragments of the dust layer) to their interiors and the possibility of generating sparks. The dust ignition may take place when an explosive atmosphere comes into contact with a heated surface. The source of ignition may also be a layer of settled dust or any flammable solid, which would be ignited as an effect of contact with a heated surface. Flammable dust settled on a heated surface absorbs heat from it and consequently poses a fire hazard. In real conditions such surfaces may comprise all types of electrical or mechanical appliances, which during their operation, or during a breakdown, generate surplus (excess) heat volumes. The dust that settles on the surface of appliances hinders the heat exchange between the appliance and the surroundings and absorbs heat, which may as a result lead to a considerable temperature increase in the dust layer. Hence in explosion preventing the knowledge of combustible properties of dust is crucial, as it determines the potential fire and explosion hazard as a consequence of it coming into contact with a heated surface.

They include values of the minimum ignition of dust in the form of a cloud and accumulated in a layer, determined on the basis of the standard PN-EN 50281-2-1:2002 [8] and PN-EN ISO/IEC 80079-20-2 [9]:

- the minimal ignition temperature of a cloud dust (MTCD) is the lowest temperature of a hot interior wall in a furnace, in which the ignition of the dust cloud takes places in air contained inside the furnace [10],

- the minimal ignition temperature of a dust layer (MITL) is the lowest temperature of a hot surface, in which ignition takes place of a dust layer settled on its surface of a determined thickness [10].

Dust may be ignited at the time of contact of a layer or cloud with a heated surface. Examples of heated surfaces in industrial conditions may comprise heaters, dryers and heating coils; and the source of dangerous temperatures may also be mechanical processes and processes involving machines that generate heat fluxes. They comprise devices, protective systems, parts and subassemblies, which convert mechanical energy into thermal one (i.e. friction coupling, mechanical brakes). Ignition may also take place as a result of insufficient greasing of moving parts in bearings, shaft culverts and seals, as well as if foreign bodies permeate into places of moving parts in appliances situated adjacent to each other, which may cause a quick rise in surface temperature [5].

According to the literature $[2,3]$ it were observed:

- the higher the contents of moisture in the sample of the dust, as a rule the higher the minimum dust ignition temperature (in case of clouds); 
- the higher the contents of non-flammable fractions in the sample, the higher the minimum dust ignition temperature;

- the lower the average size of dust particles, the lower the minimum dust ignition temperature;

- the higher the contents of volatile parts (VM), the lower the minimum dust ignition temperature;

- the higher the oxygen concentration in the surroundings, the lower the minimum dust ignition temperature.

The ability of a heated surface to cause ignition is strictly correlated with the type and concentration of the dust present in the mixture with air, the time of contact of dust with a heated surface and the air flow rate. This ability increases with the increase in temperature and surface of a heat source. The surface temperature that causes the dust ignition depends on the dimensions and shape of the heated element, dust concentration gradient in the vicinity of its surface and the type of heated material.

The exothermal nature of the oxidation reaction, and subsequently the combustion of inflammable dust, allows additionally easy progress in materials that have a developed surface of flammable material with an oxidizer. Another source of ignition of a dust cloud may also be a layer of incandescent settled dust, which was raised to the surroundings of the premises or to the given devices, for example as a consequence of an air blast. The accumulation of dusts in industrial plants may take place among others on tanks and containers, as well as in cyclones, dryers and filters. The increased temperature in equipment that processes fragmented substances should be regulated without delay.

To avoid the hazard connected with ignition of a dust layer or cloud caused by industrial devices it is necessary that:

- electric power of circuits is limited in a way that impedes the generation of arc discharges, sparking or temperatures able to ignite inflammable dust,

- the surface temperature, on which dust may be accumulated or which may border with the dust cloud, is lower than the maximum admissible surface temperature (MDTP) for devices,

- all sparking electric parts or parts that have a temperature higher than ignition temperature are enclosed by a housing to provide protection from potential permeation of dust,

- all other ignition sources are ruled out.

The minimum dust ignition temperature value is crucial during developing a concept for explosion protection, in particular with respect to eliminating potential ignition sources. A significant amount of dusts of organic origin, such as flour, becomes ignited if the formed dust cloud comes into contact with a surface having the temperature of ca. $400-500^{\circ} \mathrm{C}$. Ignition of a dust cloud at a lower temperature will also be possible in specific conditions, e.g. at lower moisture contents in the sample, relatively small dimensions of dust particles or intense turbulences. In such an event occurs glowing or smouldering at a temperature of $200{ }^{\circ} \mathrm{C}$ (flameless combustion) of dust, which may start an explosion.

All safety conditions connected with the devices are designated for the operation within the range of rated values and on the assumption of correct assembly and maintenance during use. The intensity and duration of internal and external damage in the device should be limited to values that are not likely to cause failure [6].

The maximum acceptable surface temperature (MAST) of appliances used in explosion zones is determined according to PN-EN 60079-14:2009 by applying the appropriate safety margin which should take into account the values of MITL and MTCD in such a way that:

- MAST of devices used in zones threatened by explosion of combustible dusts may not exceed $2 / 3$ the MTCD value,

- MAST of devices used in zones threatened by explosion of combustible dusts may not exceed a value lower than $75 \mathrm{~K}$ than MITL for dust layers up to $5 \mathrm{~mm}$ thick. 
According to standard, this MAST determination procedure is to be adopted if the thickness of the settled dust layer in industrial conditions is controlled, removed or not, or in a design method limited to $5 \mathrm{~mm}$. If there is a possibility of a dust layer having a thickness ranging from 5 to $50 \mathrm{~mm}$ accumulating on appliances, and the minimum ignition temperature of a layer $5 \mathrm{~mm}$ thick is equal to or exceeds $250{ }^{\circ} \mathrm{C}$, the MAST value shall be adopted according to the diagram presented on [10].

The classification area of explosion zones presented in PN-EN 60079-14:2009 does not specify the impact of a dust layer on the explosion hazard. The fire and explosion hazard caused by accumulated dust layers should be analysed for layers and clouds separately. Three hazards may be distinguished caused by dust layers [10]:

- an explosion taking place inside a premise may cause a dust layer to be raised and a cloud created, the ignition of which would cause consequent explosions of bigger destructive consequences than the initial one. Hence dust layers should always be controlled to reduce the risk of potential explosions;

- dust layers may be subject to ignition from a heat flux created by the device, on which such a layer has settled. In such a case a bigger fire hazard than explosion risk may be expected;

- an elevated dust layer forms a cloud and may be ignited from a hot surface and then lead to the explosion of the cloud.

Experience and practice suggest that values of MTCD tend to be much higher than MITL for the given dust type. The MITL value for lignite (a type of brown coal) is within the range $230-250{ }^{\circ} \mathrm{C}$, and the $\mathrm{MTCD}$ values are within the range of 410 to $450^{\circ} \mathrm{C}$ [10]. Temperature ranges of surfaces in a few types of appliances, with the exception of industrial furnaces, may be identical to those ranges. The fire and explosion risks caused by dusts depend mainly on its type and the layer thickness, hence activities connected with dust removal (cleaning up) in an industrial plant are crucial in reducing the risk of their occurrence. The selection of devices used in the presence of flammable dusts is directly influenced by the effectiveness of dust cleaning. What is more, the sole usage of the value of frequency at which dust is removed to control the risk of explosion in an industrial plant is insufficient. The complete analysis should also take into account the rate at which dust settles, which depends on the sequence and rate of dust generation, for example a secondary source of dust generation with a high rate of dust settlement may lead to the formation of a dangerous dust layer much quicker as compared to a source with the first release degree having a lower rate of dust settlement [7].

The accumulation of a dust layer in a plant depends to a major extent on:

- the rate of its accumulation,

- the intensity of dust generation from its source (effectiveness of dust formation),

- the effective dust removal (cleaning activities).

Contrary to gases and vapours of liquids, a specific property of dusts is the dependence of flammability and explosiveness parameters not only on the properties of the given dust type (its volatility, contents of flammable components etc.), but also on such factors as pulverisation or humidity.

\section{Material and methods}

\subsection{Description of tested dusts}

The tests have been conducted using four types of dusts having varying crushing levels, and namely:

- dust of Tobacco Golden Virginia with grading of $\leq 500 \mu \mathrm{m}$, 
- dust of Tobacco Alsbo Black with grading of $\leq 500 \mu \mathrm{m}$,

- dust of Tobacco West Red with grading of $\leq 500 \mu \mathrm{m}$,

- dust of Snuff White Elephant with grading of $\leq 200 \mu \mathrm{m}$.

The determination of the MITL values was tested with the use of dust layers - 5 or 12.5 $\mathrm{mm}$. The tobacco dust was a typical marked product.

The first stage of obtaining peat dust was grinding the material in ring-roller mill. Next, dust samples were prepared by screening through a vibrating sieve of defined standardized diameter. This guaranteed that the tested sample of dust contained grains of diameter not greater than the nominal sieve opening size.

\subsection{Description of test methods}

In accordance with the standard [8,9], two methods of measuring the minimum ignition temperatures of dust may be applied:

- Method A - this method comprises the determination of the minimum temperature of a dust layer with a specified thickness on a heating plate.

- Method B - this method comprises the determination of the minimum ignition temperature of the dust cloud or other ground materials.

The testing (method A) is to be continued until ignition is observed. In accordance with the standard, it shall be considered that ignition of a dust layer has taken place when:

- Glowing or flaming burning is observed, or

- The measured temperature has achieved the value of $450^{\circ} \mathrm{C}$, or

- The measured temperature has exceeded by $250^{\circ} \mathrm{C}$ the temperature of the heating plate.

As regards points 1) and 2) ignition is considered not to have taken place if it is possible to prove that the reaction does not turn into a glowing or burning process. Glowing is an undeniable process which is the most frequent symptom of ignition of a dust layer.

It is considered that ignition of a dust cloud has taken place if a flame is visible beyond the bottom end of the oven pipe. Nevertheless a slight delay is admissible for ignition of a duct cloud. Sparks without a flame are not taken to indicate ignition of a dust cloud.

The results of the executed tests related to values of minimum ignition temperatures for particular dust layers placed on a heating plate were presented in table 3. Experimental errors are about $\pm 10^{\circ} \mathrm{C}$.

\section{Results}

Table 1 presents sample results of the MITL and MTCD values in the function of the layer thickness of selected dusty tobacco products, table 2 present MAST values for devices operating in the presence of those all tested dusts. During the determination of characteristic parameters of materials, when a heated surface is the source of ignition, attention should also be drawn to the possibility of reducing ignition temperatures caused by pollution by other substances, including oil. A possible cause of ignition of inflammable dust of tobacco product (natural) origin, accumulated over a longer time (at a relatively low initial temperature of the material and the surroundings) in the form of layers (piles) in forbidden places can be their self-heating. The lack of supervision and neglecting such circumstances can initiate processes which can lead to the temperature inside the material being raised. The effect of self-heating of substances may take place as a consequence of slow exothermal reactions of material with oxygen or as an effect of biological or physical processes. For this type of processes the contents of water in dust is conducive to putrefaction and bacteria proliferation. Dust accumulated in one major industrial plant increases the explosion hazard. Self-heating is a process which is frequently accompanied 
by the release of carbon dioxide. Monitoring of its concentration is one of the methods that allow discovering this type of ignition source.

Table 1. Dependence of the minimal ignition temperature of a dust layer (MITL) in the function of the layer thickness and minimal ignition temperature of a dust cloud (MTCD) on the chosen tobacco product dust.

\begin{tabular}{|c|c|c|c|c|c|c|}
\hline \multirow{3}{*}{ Type of dust } & \multirow{3}{*}{$\begin{array}{c}\text { Grain size } \\
{[\mu \mathrm{m}]}\end{array}$} & \multirow{3}{*}{$\begin{array}{c}\text { Humidity } \\
{[\%]}\end{array}$} & \multirow{3}{*}{$\begin{array}{c}\text { Average bulk } \\
\text { density } \\
{\left[\mathrm{kg} / \mathrm{m}^{3}\right]}\end{array}$} & & & \multirow{3}{*}{$\begin{array}{l}\text { MTCD } \\
{\left[{ }^{\circ} \mathbf{C}\right]}\end{array}$} \\
\hline & & & & \multicolumn{2}{|c|}{$\begin{array}{c}\text { Thickness of dust } \\
\text { layer [mm] }\end{array}$} & \\
\hline & & & & 5 & 12.5 & \\
\hline $\begin{array}{c}\text { Tobacco Golden } \\
\text { Virginia }\end{array}$ & $\leq 500$ & 26.202 & 235 & 330 & 290 & 640 \\
\hline $\begin{array}{c}\text { Tobacco Alsbo } \\
\text { Black }\end{array}$ & $\leq 500$ & 16.889 & 390 & 320 & 310 & 680 \\
\hline $\begin{array}{c}\text { Tobacco West } \\
\text { Red }\end{array}$ & $\leq 500$ & 12.773 & 220 & 330 & 290 & 630 \\
\hline $\begin{array}{l}\text { Snuff White } \\
\text { Elephant }\end{array}$ & $\leq 200$ & 8.104 & 180 & 300 & 280 & 400 \\
\hline
\end{tabular}

Table 2. Values of the maximum acceptable surface temperature (MAST) of a machine operating in the presence of tested tobacco dust atmosphere Setting Word's margins.

\begin{tabular}{|c|c|c|c|}
\hline \multirow{2}{*}{ Type of dust } & \multicolumn{3}{|c|}{ MAST [ ${ }^{\mathbf{C}} \mathbf{C}$} \\
\cline { 2 - 4 } & layer -5 $\mathbf{~ m m}$ & layer - 12.5 $\mathbf{~ m m}$ & cloud \\
\hline Tobacco Golden Virginia dust & 255 & 200 & 427 \\
\hline Tobacco Alsbo Black & 245 & 200 & 453 \\
\hline Tobacco West Red & 255 & 200 & 420 \\
\hline Snuff White Elephant & 225 & 140 & 267 \\
\hline
\end{tabular}

Results of research conducted in the Main School of Fire Service related to the determination of MITL and MTCD values for combustible dusts allow the formulation of the following conclusions:

- Snuff represented in this study by a product called White Elephant was found to be most pulverised and had the lowest ignition temperatures of layers and clouds. Combustion progressed much quicker, and the considerable pulverisation caused the proper surface of the sample to be much bigger, thanks to which snuff gained a bigger surface to gaining and accumulating thermal energy. In a cloud sample a sample of this tobacco product was maintained for the longer time as a dust and air suspension. The extended exposure time of the suspension of this sample in the interior of the heated silicate pipe enabled achieving the lowest minimum ignition temperature of the cloud from among all the tested samples.

- The determination of the minimum ignition temperature for dusts formed in a layer, allowing for the grading composition of dust and the thickness of a dust layer, affects significantly the correct evaluation and selection of applies which are to be used in dust logged premises. This is connected with limiting hazards caused by inflammable tobacco dusts. 
- The fineness degree of dusts affects the value of the minimum combustion temperature. The increase in the fineness degree of a dust layer tends to reduce the ignition temperature of a layer and a cloud.

- Increasing the dust layer thickness from $5 \mathrm{~mm}$ to $12.5 \mathrm{~mm}$ entails a reduction in ignition temperature and prolongation of time after which it is observed. Lower heat losses caused by the isolating effect in the event of a thicker layer lead to a temperature rise in the layer. As an effect of insufficient heat release to the surroundings, a combustion reaction of a dust layer may be initiated. Also to be borne in mind is the layer thickness of the tobacco product, and for a $5 \mathrm{~mm}$ layer the ignition temperature was on average by $30^{\circ} \mathrm{C}$ bigger than for a $12.5 \mathrm{~mm}$ layer of the same product. Concurrently the ignition process was found to take place much quicker than for a thicker layer. As a $12.5 \mathrm{~mm}$ layer has a bigger amount of material, it required a longer heating time. Furthermore, the testing allowed the presumption that materials with a lower bulk density tended to become heated up much quicker. As a rule the thickness of an accumulated layer affects to a much larger extent the reduction of the minimum dust ignition temperature in a layer than the size of grains in such dust.

\section{Conclusion}

During the execution of experimental research related to the susceptibility of dusts to ignition from a heated surface the following observations were made:

- snuff represented in this study by a product called White Elephant was found to be most pulverised and had the lowest ignition temperatures of layers and clouds. Values of the maximum acceptable surface temperature (MAST) of a machine operating in the presence of tested snuff is the smallest (among tested dust) $-140{ }^{\circ} \mathrm{C}$,

- the impact of air flow on hastening the flameless combustion and the propagation of smouldering spots during the operation of a ventilation exhaust,

- the impact of humidity contained in dust on increasing the time to ignition. As water has a considerable evaporation heat, it delays the initiation of dust layer ignition.

- the thicker the accumulated dust layer, the most clearly increases the fire and explosion hazard.

- the conducted experimental testing allows minimising the hazards and justifies the necessity of ensuring particularly thorough and frequent removal of compiled dusts, respecting technological regimes and the required frequency of implementation of inspections and maintenance activities of all machines and plant used in the technological process.

The paper was carried out under research project no. DOBR-BIO4/050/13009/2013: Development of system solutions to support the execution of post-fire investigations based on cutting-edge technologies, including technical and IT tools, financed by the National Centre for Research and Development.

\section{References}

1. Data of the National Association of the Tobacco Industry, www.kspt.org.pl (2017)

2. J. A. Abbot, Prevention of fires and explosions in Dryers (Institute of Chemical Engineers, UK, Rugby, 1990)

3. R.K Eckhoff., J. Loss Prevent. Proc., 18 (2005)

4. V. Babrauskas, Ignition handbook (Fire Science Publishers, Issaquah, 2003)

5. Z. Yuan, N. Khakzad, Process Saf. Environ., 98 (2015) 
6. J. Barton, Dust explosion. Prevention and protection. A practical guide (Institution of Chemical Engineers, UK, Rugby, 2002)

7. M. Półka, Z. Salamonowicz, M. Woliński, B. Kukfisz, Procedia Engineering, 45 (2012)

8. EN 50281-2-1: 2002 Electrical appliances for use in the presence of inflammable dusts. Part 2-1: Test methods - Determination methods of the minimum dust ignition point

9. ISO/IEC 80079-20-2:2016/Cor 1:2017, Explosive atmospheres - Part 20-2: Material characteristics - Combustible dusts test methods - Technical Corrigendum 1

10. PN-EN 60079-14:2014, Explosive atmospheres -- Part 14: Electrical installations design, selection and erection 